\title{
FORMULATION AND EVALUATION OF BILAYERED FELODIPINE TRANSDERMAL PATCHES: IN VITRO AND EX VIVO CHARACTERIZATION
}

\author{
KEERTHANA M ${ }^{1}$, SHIRISHA $\mathbf{S}^{\mathbf{1}^{*}}$, SAHOO SUNIT KUMAR ${ }^{2}$, MADHUSUDAN RAO $\mathbf{Y}^{3}$ \\ ${ }^{1}$ Department of Pharmaceutics, Vaagdevi College of Pharmacy, Kishanpura, Warangal, Telangana, India. ${ }^{2}$ Department of Pharmaceutics, \\ UDPS, Utkal University, Vani Vihar, Bhubaneswar, Odisha, India. ${ }^{3}$ Department of Pharmaceutics, Vaagdevi Institute of Pharmaceutical \\ Sciences, Bollikunta, 506005, Warangal, Telangana, India. Email: suddala.shirisha@gmail.com
}

Received: 18 November 2020, Revised and Accepted: 13 January 2021

ABSTRACT

Objective: Felodipine (FD) is an effective Biopharmaceutics Classification System Class II calcium channel blocker mainly used in the management of hypertension and angina pectoris. It has poor solubility and low oral bioavailability $(15 \%)$. To overcome these disadvantages and to maintain constant plasma concentration for maximum therapeutic activity, there is a need to design an alternative route, that is, transdermal route. The pharmacokinetic parameters make FD a suitable candidate for transdermal delivery. The present investigation consists of the study of in vitro and ex vivo skin flux of FD from bilayered transdermal patches.

Methods: The patches were fabricated by solvent casting method using hydrophilic and hydrophobic polymer with different composition. Tween 80 incorporated as solubilizer, polyethylene glycol 600 as plasticizer, menthol, eucalyptus oil, and lemongrass oil used as permeation enhancers, respectively. The prepared transdermal drug delivery system was extensively evaluated for in vitro release, ex vivo permeation through pig ear skin, moisture content, moisture absorption, water vapor transmission, and mechanical properties. The physicochemical interaction between FD and polymers was investigated by Fourier-transform infrared (FTIR) spectroscopy.

Results: All the formulations exhibited satisfactory physicochemical and mechanical characteristics. A flux of $35.2 \mu \mathrm{g} / \mathrm{cm}^{2} \mathrm{~h}, 27.9 \mu \mathrm{g} / \mathrm{cm}^{2} \mathrm{~h}, \mathrm{and}$ $25.25 \mu \mathrm{g} / \mathrm{cm}^{2} \mathrm{~h}$ was achieved for optimized formulations containing lemongrass oil, eucalyptus oil, and menthol, respectively, permeation enhances. Values of tensile strength $\left(0.0652 \pm 0.034 \mathrm{~kg} / \mathrm{mm}^{2}\right)$ and elongation at break $\left(0.8749 \pm 0.0 .0029 \% \mathrm{~mm}^{2}\right)$ revealed that formulation F9 was strong but not brittle. Drug and excipients compatibility studies showed no evidence of interaction between the active ingredient and polymers.

Conclusion: Bilayered FD transdermal patches could be prepared with required flux and suitable mechanical properties.

Keywords: Felodipine, Bilayered transdermal patches, Permeation enhancer, In vitro release, Ex vivo permeation, Flux.

(c) 2021 The Authors. Published by Innovare Academic Sciences Pvt Ltd. This is an open access article under the CC BY license (http://creativecommons.org/ licenses/by/4.0/) DOI: http://dx.doi.org/10.22159/ajpcr.2021v14i3.40290. Journal homepage: https://innovareacademics.in/journals/index.php/ajpcr

\section{INTRODUCTION}

Felodipine (FD) is a dihydropyridine calcium channel blocker mainly used to treat high blood pressure and angina pectoris [1]. It is rapidly absorbed after oral administration but it undergoes extensive firstpass hepatic metabolism, leading to poor bioavailability of $15 \%$ [2]. The low oral bioavailability confines its use, thus an alternative route of administration is desirable to deliver high concentration in blood to treat management in hypertension and angina.

Among the various routes of novel controlled drug delivery systems, transdermal route is most preferred route for low bioavailability drug, thus achieving the systemic effect. Transdermal drug delivery system (TDDS) is self-contained discrete dosage form when which applied to the skin it delivers drug through the skin at controlled rate to the systemic circulation [3]. Its potential advantage is overcoming hepatic first pass metabolism thereby increasing bioavailability of the drug molecule [4]. Moreover, it provides convenient, painless self-administration, termination of drug action is possible in case of any toxicity reactions are occurred. Greater patient compliance due to avoiding multiple dosing, it also provides constant and prolonged drug levels in plasma $[5,6]$.

From both physicochemical (low molecular weight $384.25 \mathrm{~g} / \mathrm{mol}$, low dose $10 \mathrm{mg}$ ) and pharmacokinetic (absolute bioavailability about $15 \%$ and $\log$ P, $1-3)$, FD was considered to be a suitable candidate for transdermal delivery [7]. Physical techniques such as iontophoresis, electroporation, sonophoresis, and microneedles and chemical penetration enhancers such as solvents, surfactants, fatty acids, and terpenes are used to increase transdermal permeation rate. In the present investigation, menthol, eucalyptus oil, and lemongrass oil are used as permeation enhancers. In the initial trials which were made with monolayer patches, drug shows precipitation in primary layer. To avoid this precipitation, bilayered matrix transdermal patches were developed. The objective of the present investigation was development of bilayered transdermal therapeutic system for FD and to evaluate physicochemical, mechanical properties, in vitro release, and ex vivo permeation through pig ear skin [8-10].

\section{METHODS}

Materials

FD is a gift sample from Hetero Labs, Hyderabad. Hydroxypropyl methylcellulose (HPMC) E15 and Eudragit RL PO procured from Qualikems Fine Chem. Pvt. Ltd. Polyethylene glycol (PEG) 600, methanol, and dichloromethane (DCM) were of analytical grade purchased from Research-Lab Fine Chem. Industries, Mumbai. Menthol, eucalyptus oil, and lemongrass oil were obtained from SD Fine Chemicals, Maharashtra, India.

\section{Methods}

Development of bilayered transdermal systems

Bilayered matrix type transdermal patches were prepared by solvent casting method with different ratios of HPMC E15 as primary polymeric layer, Eudragit RL PO as secondary polymeric layer, primary polymer 
was added to $20 \mathrm{ml}$ of solvent mixture (DCM and methanol, 1:1) and allowed to stand for $6 \mathrm{~h}$ to swell. Small amount of polymer was added to solvent mixture to prevent the lumps. Weighed accurate amount of FD was dissolved in $5 \mathrm{ml}$ of solvent mixture and added to the polymeric solution and mixed thoroughly to get uniform solution. Polyethylene glycol 400 was added to polymer mixture as a plasticizer and vortex for $5 \mathrm{~min}$. The total polymer mixture was set aside for $10 \mathrm{~min}$ to remove entrapped air, then transferred to Petri plate. Then, secondary polymeric solution was prepared by dissolving required quantity of Eudragit RL PO and required amount of PEG 600 in $15 \mathrm{ml}$ of solvent mixture and poured over the primary layer which is present in Petri plate and allowed to dry at room temperature. One funnel was placed over the Petri plate in inverted position to control the rate of evaporation of solvent. The developed patches were removed carefully, cut into required size (3.14 $\mathrm{cm}^{2}$ ), and stored in desiccators for further studies. Patches containing penetration enhancers $(1 \% \mathrm{v} / \mathrm{v})$ menthol, eucalyptus oil, and lemongrass oil were also prepared in the same method explained above by adding permeation enhancer with required amount to the polyethylene glycol and then mixed with polymeric solution [11-14]. Fabrication method and composition of details of patches are shown in Table 1.

\section{Evaluation of physicochemical parameters}

Six films from each formulation weighed individually and average weight was calculated. Thickness of the patch was measured at six different points of patch using screw gauge. Patches from each formulation were taken and cut into $4 \mathrm{~cm}^{2}$ pieces and weighed. The pieces were taken into $100 \mathrm{ml}$ volumetric flask, dissolve the patch in $2 \mathrm{ml}$ of solvent mixture (methanol:DCM) make up to $100 \mathrm{ml}$ with $\mathrm{pH} 6.8$ phosphate buffer. The above solution was filtered using $0.45 \mu \mathrm{m}$ membrane filter and drug content was analyzed using ultraviolet (UV)-visible spectrophotometer at $364 \mathrm{~nm}$. The folding endurance was determined manually by folding a small strip of the patch repeatedly at the same place until it was broke. The number of the times the strip could be folded at the same place without breaking gave the folding endurance $[15,16]$.

\section{Moisture absorption}

The patches were weighed accurately and placed in desiccators containing $100 \mathrm{ml}$ of saturated solution of aluminum chloride, which maintains $79.5 \%$ relative humidity (RH), after 3 days, the patches were taken out and weighed. The percentage of moisture absorption was calculated as difference between final and initial weight of the patch with respect of initial weight of the patch.

$$
\text { Moisture absorption }=\frac{\text { Finalweight }- \text { Initial weight }}{\text { Final } \text { weight }} \times 100
$$

\section{Moisture content}

Transdermal films were weighed accurately and placed in desiccators containing calcium chloride for $24 \mathrm{~h}$ at $40^{\circ} \mathrm{C}$. The final weight was noted until there was no further increase in patch weight. The percentage of moisture content was calculating by the following formula.

$$
\text { Moisture content }=\frac{\text { Initial weight }- \text { final weight }}{\text { Initial weight }} \times 100
$$

\section{Water vapor transmission rate (WVTR)}

It was performed according to method described by use glass vials of equal diameter transmission cells. One gram of calcium chloride placed in the cell and the patch was fixed on to the brim. The cells were accurately weighed and placed in a desiccators containing potassium chloride to maintain a RH $84 \%$. The cells were taken out and weighed. Water vapor transmitted calculated by the following formula.

$$
\text { WVTR }=\frac{\text { Final weight }- \text { Initial weight }}{\text { Tme } \times \text { Area }}
$$

\section{Mechanical properties}

Mechanical properties of the patches were tested using a microprocessor-based advanced force gauze (Ultra Test, Mecmesin, UK) equipped with a $25 \mathrm{~kg}$ load cell. The dimensions of film strip were $60 \times 10 \mathrm{~mm}$ and free from air bubbles or physical imperfections were pulled with strips to a distance held between two clamps positioned at a distance of $3 \mathrm{~cm}$ during measurement the clamp at a rate $2 \mathrm{~mm} /$ still the transdermal film broke the force and elongation was measured, when the film broke. The mechanical properties calculated by the following formulae [17].

$$
\text { Tensile strength }=\frac{\text { Force at break }(\mathrm{kg})}{\text { Initial cross section of the sample }\left(\mathrm{mm}^{2}\right)}
$$

$$
\begin{aligned}
& \text { Elongation at } \\
& \operatorname{break}\left(\% \mathrm{~mm}^{2}\right)
\end{aligned}=\frac{\text { Increase in length }}{\begin{array}{l}
\text { Original length }(\mathrm{mm}) \times \\
\text { cross sectional } \operatorname{area}\left(\mathrm{mm}^{2}\right)
\end{array}} \times 100
$$

\section{In vitro drug release studies}

In vitro drug release studies are carried out using unique selling proposition -type 5 apparatus (paddle over disc method). The disc assembly holds the transdermal system at the bottom of the vessel. The temperature is maintained at $32^{\circ} \mathrm{C} \pm 0.5$. A distance between the paddle blade and surface of the disc assembly is $25 \mathrm{~mm}$ which should be maintained during the test. The vessel containing $900 \mathrm{ml}$

\begin{tabular}{|c|c|c|c|c|c|c|c|c|c|}
\hline \multicolumn{10}{|l|}{ Primary layer } \\
\hline Ingredient/code & F1 & F2 & F3 & F4 & F5 & F6 & F7 & F8 & F9 \\
\hline Felodipine (mg) & 155 & 155 & 155 & 155 & 155 & 155 & 155 & 155 & 155 \\
\hline HPMC E15 (mg) & 775 & 930 & 1085 & 1240 & 1395 & 1550 & 930 & 930 & 930 \\
\hline PEG $600(\mathrm{~mL})$ & 155 & 186 & 217 & 248 & 279 & 310 & 186 & 186 & 186 \\
\hline Menthol (mL) & - & - & - & - & - & - & 9.36 & - & - \\
\hline Eucalyptus oil (mL) & - & - & - & - & - & - & - & 9.36 & - \\
\hline Lemongrass oil (mL) & - & - & - & - & - & - & - & - & 9.36 \\
\hline Tween $80(\mathrm{~mL})$ & - & - & - & - & - & - & 200 & 200 & 200 \\
\hline Methanol (mL) & 12.5 & 12.5 & 12.5 & 12.5 & 12.5 & 12.5 & 12.5 & 12.5 & 12.5 \\
\hline DCM $(\mathrm{mL})$ & 12.5 & 12.5 & 12.5 & 12.5 & 12.5 & 12.5 & 12.5 & 12.5 & 12.5 \\
\hline \multicolumn{10}{|l|}{ Secondary layer } \\
\hline Eudragit RL PO (mg) & 300 & 300 & 300 & 300 & 300 & 300 & 300 & 300 & 300 \\
\hline PEG 600 (mL) & 155 & 186 & 217 & 248 & 279 & 310 & 186 & 186 & 186 \\
\hline Methanol (mL) & 7.5 & 7.5 & 7.5 & 7.5 & 7.5 & 7.5 & 7.5 & 7.5 & 7.5 \\
\hline DCM (mL) & 7.5 & 7.5 & 7.5 & 7.5 & 7.5 & 7.5 & 7.5 & 7.5 & 7.5 \\
\hline
\end{tabular}
of phosphate-buffered saline (PBS) of pH 6.8 containing $15 \% \mathrm{v} / \mathrm{w}$ of PEG and stirred at $25 \mathrm{rpm}$. One milliliter of samples was withdrawn at predetermined time intervals, replaced with equal volume of fresh medium. The drug content in the samples was determined by UV-visible

Table 1: Composition of bilayered transdermal patches 
spectrophotometer at $364 \mathrm{~nm}$. Cumulative amount of drug released was calculated and plotted against time [18-20].

\section{Ex vivo drug release studies}

Preparation of pig ear skin

Pig ear was obtained from slaughter house. The hair of pig ear skin was trimmed short $(>2 \mathrm{~mm}$ ) with a pair of scissors, prepared the epidermis of pig ear skin surgically by heat separation technique. Involving soaking the entire pig ear skin in water at $60^{\circ} \mathrm{C}$ for $45 \mathrm{~s}$ and followed by careful removal of epidermis. The epidermis was washed with water and used for the ex vivo skin permeability studies.

For ex vivo studies, the skin was mounted between the two compartments of Franz diffusion cell with facing stratum carenum donor compartment a dialysis membrane (HiMedia M.W cutoff 5000) placed over the patch, to secure it tightly in the way that it will not get dislodged from the skin, the receiver phase contained $20 \mathrm{ml}$ PBS of pH 6.8 containing 15\% v/v PEG which was stirred at $500 \mathrm{rpm}$ on a magnetic stirrer and the whole assembly was kept at $37 \pm 0.5^{\circ} \mathrm{C}$. Samples of $1 \mathrm{ml}$ were withdrawn at predetermined time intervals up to $24 \mathrm{~h}$, then replace the equal volume of fresh medium and analyzed using UV-visible spectrophotometer at 364 $\mathrm{nm}$. Cumulative amount of drug permeated in $\mu \mathrm{g} / \mathrm{cm}^{2}$ plotted against time and drug flux $\left(\mu \mathrm{g} / \mathrm{h} / \mathrm{cm}^{2}\right)$ at steady state was calculated by dividing the slope of linear portion of the curve by the area of skin surface $\left(3.14 \mathrm{~cm}^{2}\right)$ and the skin permeability coefficient was reduced by dividing the initial drug load. The targeted flux was calculated by the following formula [21].

$$
\mathrm{J} \text { Target }=\frac{\mathrm{C}_{\mathrm{SS}} \mathrm{Cl} \mathrm{T}_{\mathrm{T}} \mathrm{BW}}{\mathrm{A}}
$$

\section{Drug polymer interaction studies}

Fourier-transform infrared (FTIR) spectroscopy studies were carried out to determine possible interaction studies between drug and polymer utilizing the KBr pellet method (PerkinElmer FT-IR).

\section{Release kinetics}

Data of in vitro release were fit into different equations to explain the release kinetics of FD release from transdermal patches [22]. The kinetic equations used zero-order and first-order equations.

a) Zero-order release kinetics: Defines a linear relationship between the fractions of drug released versus time

$$
\mathrm{Q}=\mathrm{Kt}
$$

Where, $Q$ is the fraction of drug released at time $t$

$\mathrm{K}$ is the zero-order release rate constant

b) First-order release kinetics: Wagner states that during dissolution process exposed surface area of formulation decreased exponentially with time, suggested that the drug release from slow release formulation could be described adequately by apparent first-order kinetics.

$$
(1-Q)=-k t
$$

Models of drug release mechanism

The release data of transdermal patch were fitted into different mechanism models such as Higuchi model and Korsmeyer-Peppas model to interpret the drug release mechanism from patches.

a) Higuchi (diffusion) model: It explains a linear dependence of the active fraction released per unit square $(Q)$ on the square root of time.

$$
\mathrm{Q}=\mathrm{Kt} 1 / 2
$$

b) Korsmeyer-Peppas model: A plot of the fraction of logarithm of the percentage of drug remained against time will be linear if the release obeys Korsmeyer-Peppas equation.

$$
\log Q=\log K+n \log t
$$

\section{RESULTS AND DISCUSSION}

Weight, thickness variation, drug content, and folding endurance The physicochemical parameters such as weight variation, thickness variation, drug content, and folding endurance of the prepared transdermal patches are shown in Fig. 1 and Table 2. The range of weight the patches were from $118.2 \pm 3.06$ to $123.9 \pm 2.82 \mathrm{mg}$ and thickness ranges from $0.29 \pm 0.006$ to $0.34 \pm 0.005 \mathrm{~mm}$. When the content of HPMC E15 was increases in the patches, the weight and thickness of films are also increases. The results revealed that the transdermal films were uniform, as it was verified by relative standard deviation (RSD) value, which were $<6$. Observe the good uniformity in drug content in all transdermal patches as evidenced by low RSD values which were less than 1 . The drug content ranges from $9.29 \pm 0.034$ to $9.53 \pm 0.052$ $\mathrm{mg}$. The folding endurance numbers of patch without permeation enhancer have in the range of $102.45 \pm 1.05$ and for the films prepared with penetration enhancers were in the range of $114.33 \pm 2.08$ to $128.67 \pm 2.11$. The number of folding endurance gives the mechanical property of the transdermal films; high folding endurance number indicates that the patches have high mechanical property. The results revealed that films would not break and would maintain their integrity when applied with general skin folding when applied.

\section{Moisture absorption and moisture content studies}

Moisture content and moisture absorption studies results are shown in Table 3. The moisture content in the patches varied from $1.649 \pm 2.34$ to $2.632 \pm 3.47$. The moisture absorption in the patches was from 14.87 $\pm 0.95 \%$ to $17.567 \pm 0.54 \%$. The small moisture content in the patches helps them to remain stable and not being a completely dried and brittle film. Again, absorption of low moisture protects the transdermal patches from contamination with microbes.

\section{Mechanical properties}

The results of mechanical properties of tensile strength (TS) and elongation at break (E/B) are shown in Table 3. The mechanical properties show the patch strength and elasticity. It indicates that the polymer is soft and weak, when the values (TS and E/B) are low and polymer is hard and tough, when the values are high. Based on the all values obtained, patches having good mechanical property [6]. Optimized formulation F9 exhibited TS and E/B values $(0.0942 \pm 0.0029$ $\mathrm{kg} / \mathrm{mm}^{2}$ and $0.8749 \pm 0.054 \mathrm{~mm}^{2}$ ). Compare to all formulations, the optimized formulation F9 shows high TS and low E/B values that indicates F9 was found to be strong and flexible but not brittle.

\section{In vitro drug release studies}

The in vitro drug release profile of prepared transdermal patches is represented in Fig. 2. The setup of in vitro drug release studies shown in Fig. 3. The results of release studies showed that F2 formulation has drug release $8376.92 \pm 0.8 \mu \mathrm{g}$ in $24 \mathrm{~h}$. Hence, patches containing permeation enhancers F7, F8, and F9 showed higher drug release 9761.53 $\pm 1.5 \mu \mathrm{g}$, $10,038.46 \pm 1.4 \mu \mathrm{g}$, and 10,107.69 $\pm 1.4 \mu$ gin $24 \mathrm{~h}$, respectively, compared with formulation without enhancers. From the results and graphs, it is clear that the drug release from optimized formulation F9 containing lemongrass oil as a permeation enhancer showed higher drug release

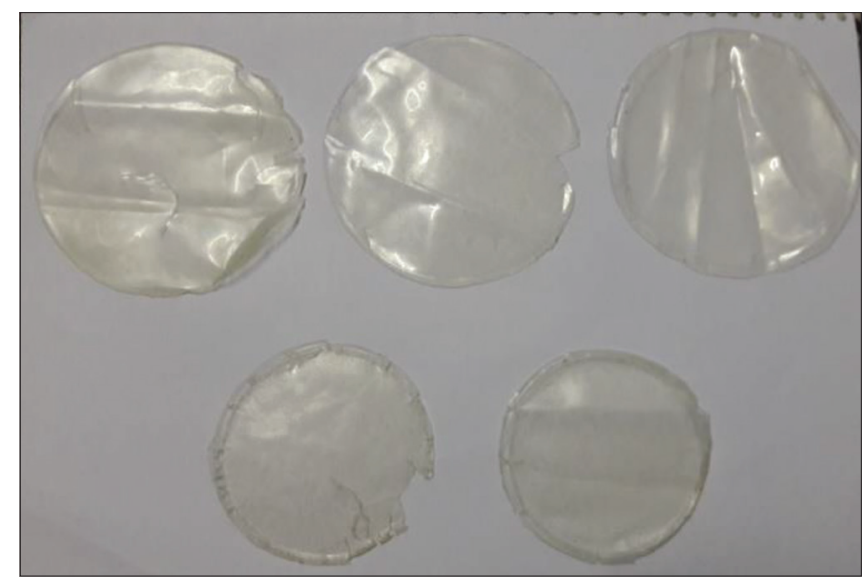

Fig. 1: Prepared transdermal formulations 


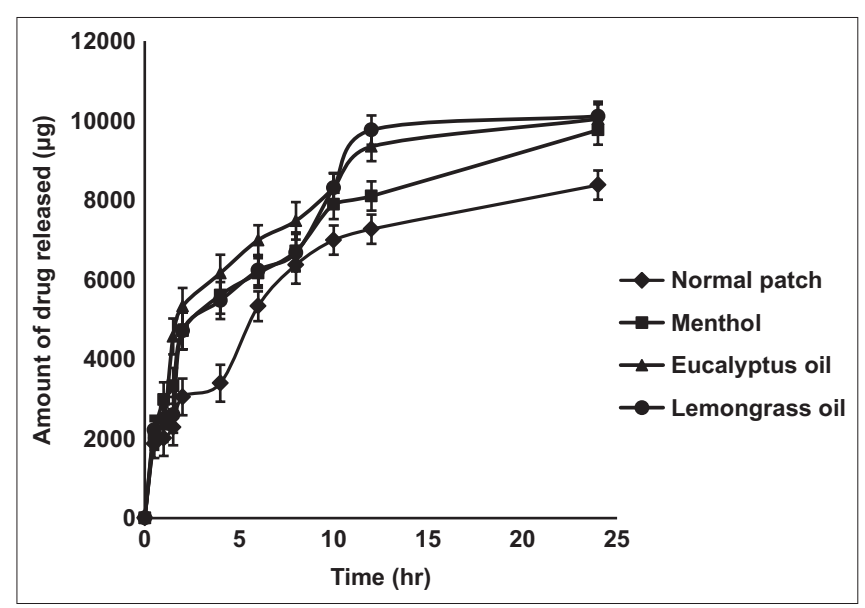

Fig. 2: In vitro drug release studies of transdermal patches. Values represent mean \pm SD

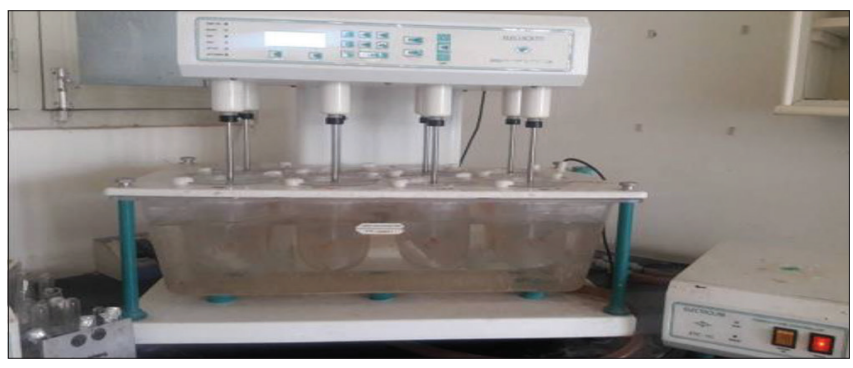

Fig. 3: Paddle over disc method for drug release studies of transdermal patches compare to all the formulations. The drug release was depends on polymer and permeation enhancer content. The data of in vitro release of all formulations well fitted into zero-order kinetics.

\section{Ex vivo permeation studies}

Ex vivo permeation studies were carried out for F2, F7, F8, and F9 formulations through pig ear skin because it was closest alternative to the human cadaver skin. The set up of ex vivo permeation studies shown in Fig. 4. The results shown in Fig. 5 reveal that F2 formulation has drug permeation $2556.76 \mu \mathrm{g}$ and flux $19.2 \mu \mathrm{g} / \mathrm{h} / \mathrm{cm}^{2}$ earlier research studies revealed that menthol (F7), eucalyptus oil (F8), and lemongrass oil (F9) were used as permeation enhancers. To increase the drug permeation, permeation enhancers (F7, F8, and F9) in the concentration of $1 \%$ $\mathrm{v} / \mathrm{v}$ were added to $\mathrm{F} 2$ formulation which showed a result of drug permeation F7 - $2866 \mu \mathrm{g}$, F8 - 3260.46 $\mu \mathrm{g}$, and F9 - $3715.38 \mu \mathrm{g}$ and flux F7 - $25.2 \mu \mathrm{g} / \mathrm{h} / \mathrm{cm}^{2}$, F8 - $27.9 \mu \mathrm{g} / \mathrm{h} / \mathrm{cm}^{2}$, and F9 $-35.2 \mu \mathrm{g} / \mathrm{h} / \mathrm{cm}^{2}$, respectively. Hence with the use of permeation, enhancer showed a good result in increase of drug permeation through pig ear skin. Plotting the cumulative amount of drug permeated per square centimeter against time in hours showed that the profile of drug permeation as it was proved by zero-order kinetics $\left(\mathrm{r}^{2}=0.974\right)$ better fit than first-order kinetics $\left(r^{2}=0.931\right)$ and Korsmeyer-Peppas $n$ value is 0.319 . The $r^{2}$ and $\mathrm{n}$ values reveal that the permeation of FD from the transdermal films followed zero-order and through anomalous mechanism.

\section{Drug-polymer interaction studies}

The FTIR (shown in Fig. 6) spectral analysis of FD alone showed that the principal peaks were observed at wave numbers of $3437.47 \mathrm{~cm}^{-1}$ (N-H stretching), $1431.12 \mathrm{~cm}^{-1}$ (C-H stretching), and $1679.09 \mathrm{~cm}^{-1}$ (C=0 stretching). The FTIR spectra of physical mixture of FD and HPMC E15 approximate superimposition of drug and polymer FTIR spectra. These results suggest that there is no interaction between drug and polymer used in the present study.
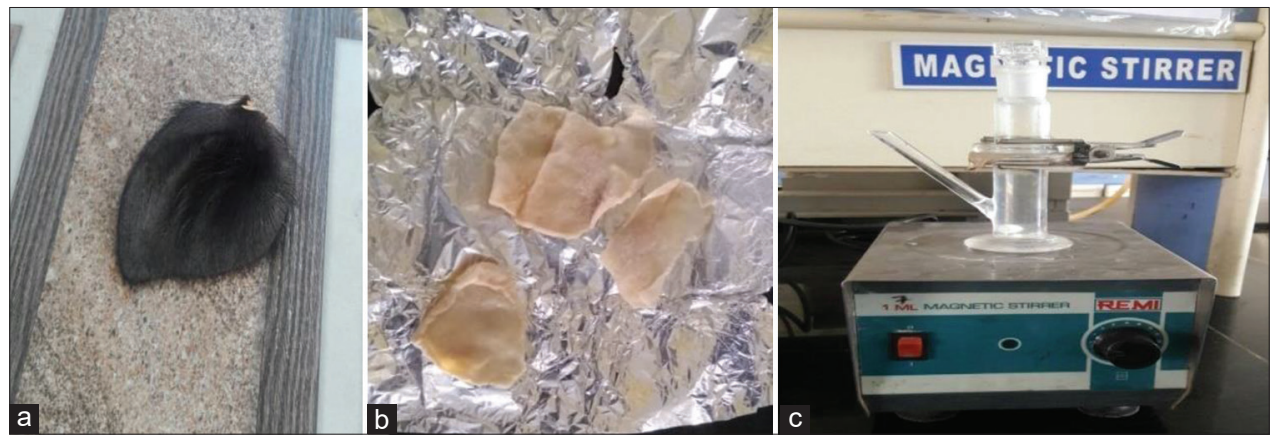

Fig. 4: (a) Pig ear skin, (b) separation of epidermis of pig ear skin, (c) arrangement of pig ear skin in Franz diffusion cell

Table 2: Physicochemical evaluation of the transdermal patches

\begin{tabular}{llllll}
\hline Formulation code & Weight variation $(\mathbf{m g})$ & Thickness $\left.^{\mathbf{a}} \mathbf{( m m}\right)$ & Drug content $^{\mathbf{b}}$ & \% Constriction $^{\mathbf{b}}$ endurance $^{\mathbf{b}}$ & Folding \\
\hline F2 & $120.6 \pm 2.6$ & $70.29 \pm 0.006$ & $9.36 \pm 0.042$ & $1.18 \pm 0.083$ & $132.45 \pm 1.05$ \\
F7 & $118.2 \pm 3.06$ & $0.32 \pm 0.010$ & $9.53 \pm 0.052$ & $2.08 \pm 0.011$ & $114.33 \pm 2.08$ \\
F8 & $128.9 \pm 2.82$ & $0.35 \pm 0.005$ & $9.29 \pm 0.034$ & $1.56 \pm 0.027$ & $251.33 \pm 5.56$ \\
F9 & $119.1 \pm 3.24$ & $0.49 \pm 0.006$ & $9.47 \pm 0.039$ & $1.88 \pm 0.036$ & $104.67 \pm 4.11$ \\
\hline
\end{tabular}

${ }^{a}$ Values represent mean \pm 6 , ${ }^{b}$ Values represent mean \pm 3

Table 3: Moisture studies and mechanical properties of transdermal patches

\begin{tabular}{|c|c|c|c|c|c|}
\hline \multicolumn{6}{|c|}{ Moisture studies mechanical properties } \\
\hline Formulation at code & \%moisture absorbed & $\%$ moisture content & WVTR $\left(\mathrm{g} / \mathrm{cm}^{2} / \mathrm{h}\right)$ & $\begin{array}{l}\text { Tensile strength } \\
\left(\mathrm{kg} / \mathrm{mm}^{2}\right)\end{array}$ & $\begin{array}{l}\text { Elongation break } \\
\left(\% \mathrm{~mm}^{2}\right)\end{array}$ \\
\hline F2 & $4.87 \pm 0.95$ & $1.649 \pm 2.34$ & $1.296 \times 10^{-4} \pm 0.028$ & $0.0940 \pm 0.0022$ & $1.4367 \pm 0.187$ \\
\hline F7 & $6.233 \pm 0.23$ & $2.103 \pm 2.87$ & $0.653 \times 10^{-4} \pm 0.016$ & $0.0793 \pm 0.0015$ & $0.9974 \pm 0.108$ \\
\hline F8 & $4.567 \pm 0.54$ & $1.944 \pm 4.99$ & $0.531 \times 10^{-4} \pm 0.029$ & $0.0788 \pm 0.0024$ & $1.1252 \pm 0.073$ \\
\hline F9 & $5.992 \pm 0.59$ & $2.632 \pm 3.47$ & $0.782 \times 10^{-4} \pm 0.034$ & $0.0652 \pm 0.0029$ & $0.8749 \pm 0.054$ \\
\hline
\end{tabular}

Values represent mean \pm 3 


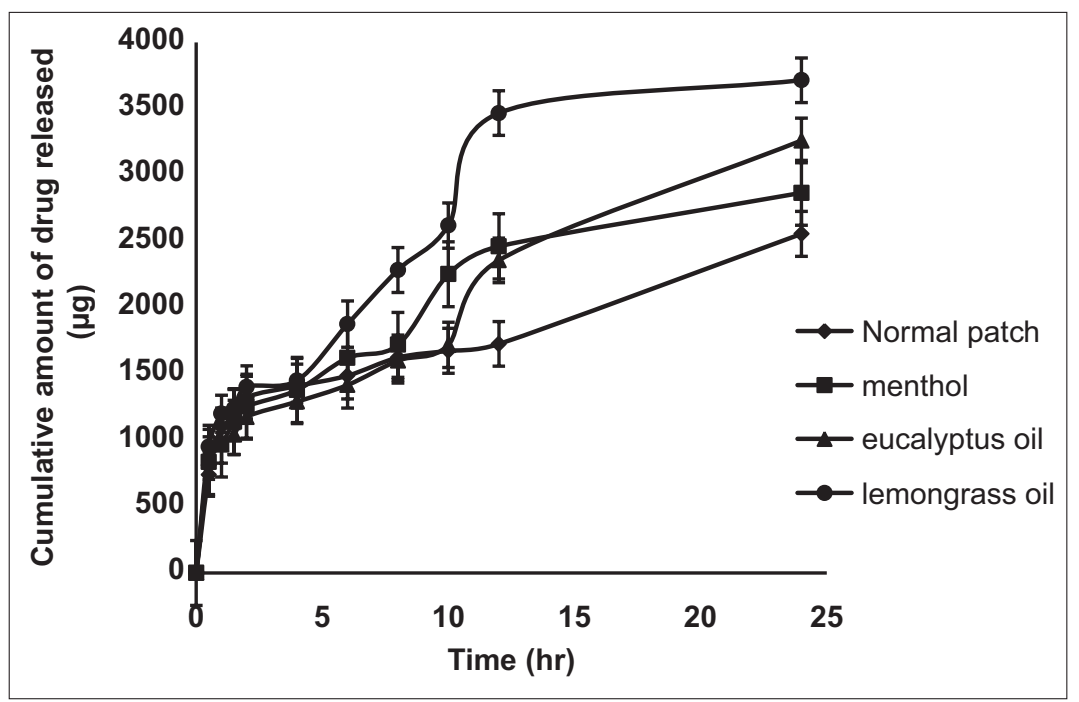

Fig. 5: Ex vivo drug permeation studies through pig ear skin. Values represent mean \pm SD
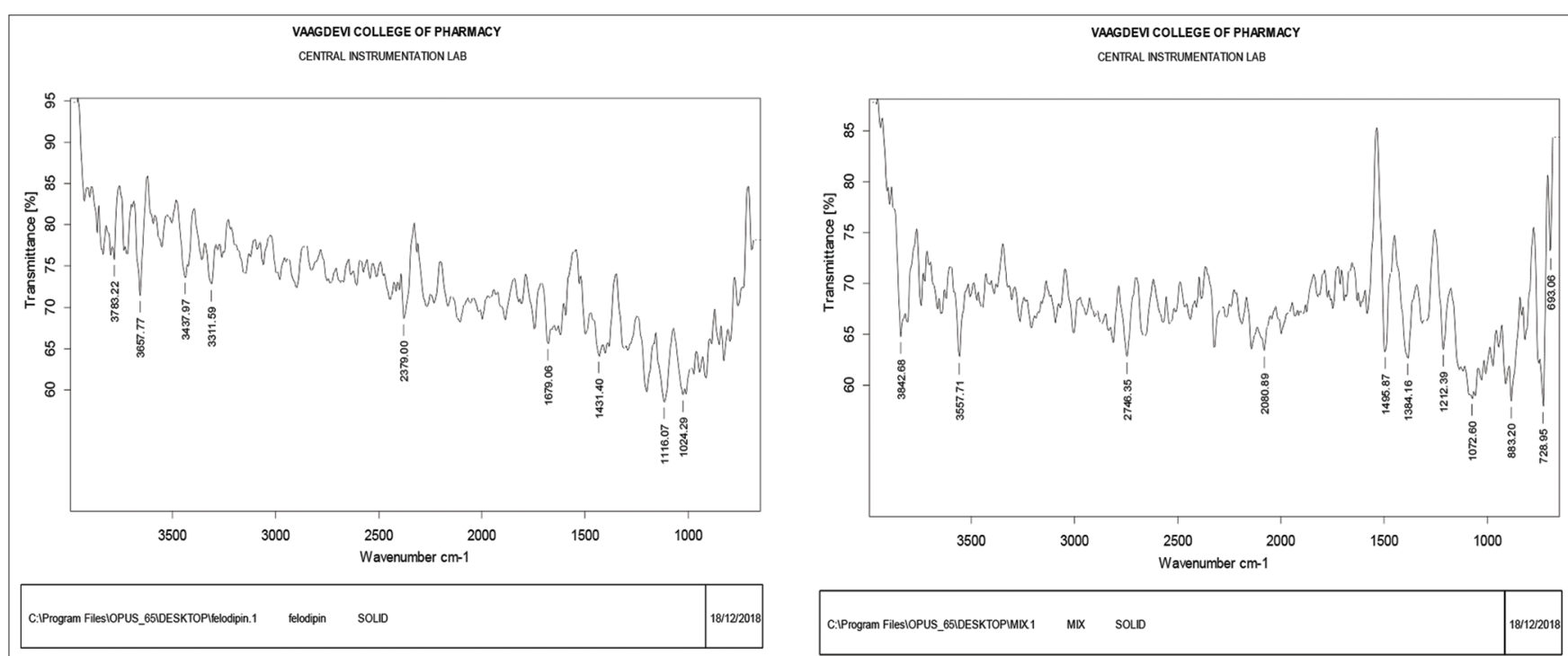

a

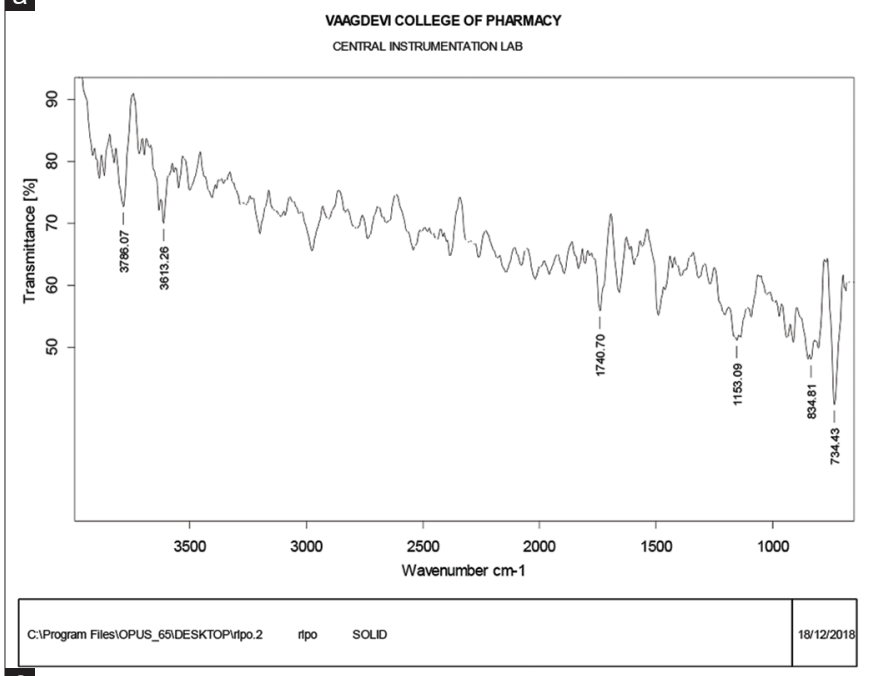

b

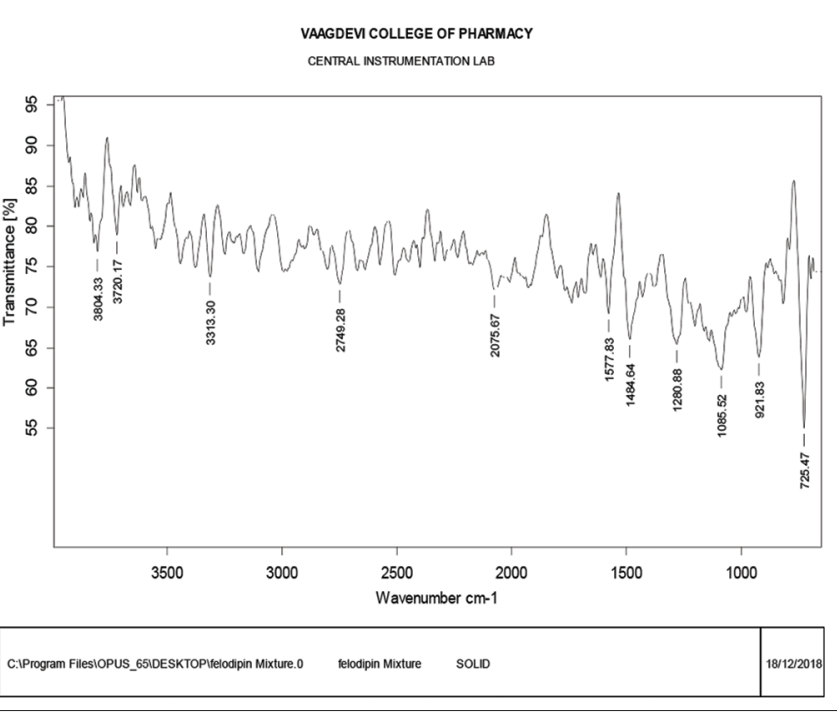

Fig. 6: Drug-excipient interaction studies (FTIR). (a) Pure drug, (b) hydroxypropyl methylcellulose (HPMC) E15, (c) Eudragit RL PO, (d) drug, HPMC E15, and Eudragit RL PO 


\section{CONCLUSION}

The present study showed that FD patch containing HPMC E15 and Eudragit RL PO in the ratio of 1:6 with 15\%v/w of PEG 600 achieved the desired objectives of TDDS such as overcoming first-pass effect, thus increases the bioavailability of FD. The polymeric patches containing FD were evaluated for physicochemical, in vitro, and ex vivo characteristics. The formulation containing HPMC E15, Eudragit RL PO, and permeation enhancer (lemongrass oil $1 \% \mathrm{v} / \mathrm{v}$ ) was found to increase higher flux $35.2 \mu \mathrm{g} / \mathrm{h} / \mathrm{cm}^{2}$. The transdermal patches with required flux could be prepared with suitable mechanical properties.

\section{ACKNOWLEDGMENT}

Authors are thankful to DST, women scientist Government of India for providing financial support for carried out the work and thankful to Hetero Labs, Hyderabad, for providing gift sample of FD drug, and also Vaagdevi College of Pharmacy for providing laboratory facilities for carried out the work.

\section{CONFLICTS OF INTEREST}

There were no conflicts of interest.

\section{AUTHORS' CONTRIBUTIONS}

The first and second authors have participated in the work including participation in the concept, preparation of patches, evaluation part, analysis of results, writing, and revision of manuscript. The third author gave the guidance and essential knowledge to whole the work.

\section{REFERENCES}

1. Ranju P, Ragini S. Anti-hypertensive drugs used for transdermal drug delivery. Asian J Pharm Educ Res 2012;1:31-52.

2. Mori D, Makwana J, Parmar R, Patel K, Chavda J. Formulation evaluation and optimization of the felodipine nanosuspension to be used for direct compression to tablet for in vitro dissolution enhancement. Pak J Pharm Sci 2016;29:1927-36.

3. Reddy YK, Reddy DM, Kumar MA. Transdermal drug delivery system. Indian J Res Pharm Biotechnol 2014;2:1094-103.

4. Gannu R, Palem CR, Yamsani V, Yamsani SK, Yamsani MR. Enhanced bioavailability of lacidipine via microemulsion based transdermal gels: Formulation optimization, ex vivo and in vivo characterization. Int $\mathrm{J}$ Pharm 2010;388:231-41

5. Chein YW. Transdermal Controlled Systemic Medication; 1987. p. 159.

6. Aulton ME, Abdul-Razzak MH, Hogan JE. The mechanical properties of hydroxypropylmethylcellulose films derived from aqueous systems Part 1: The influence of plasticisers. Drug Dev Ind Pharm 1981;7:649-68.

7. Sharma V, Yusuf M, Pathak K. Nanovesicles for transdermal delivery of felodipine: Development, characterization, and pharmacokinetics. Int J Pharm Investig 2014;2:119.

8. Pavani S, Rao YM, Kumar YS. Use of box-behnken experimental design for optimization of process variables in iontophoretic delivery of repaglinide. J Young Pharm 2016;8:350.

9. Keerthi H, Kumar PP, Rao YM. Design and characterization of atenolol transdermal therapeutic systems: Enhancement of permeability via iontophoresis. PDA J Pharm Sci Technol 2012;66:318-32.

10. Pavani S, Rao YM, Kumar YS. Comparison of enhancement of transdermal permeability of Carvedilol through physical and chemical methods. Egypt Pharm J 2015;14:103.

11. Madishetti SK, Palem CR, Gannu R, Thatipamula RP, Panakanti PK, Yamsani MR. Development of domperidone bilayered matrix type transdermal patches: Physicochemical, in vitro, ex vivo characterization. DARU J Pharm Sci 2010;18:221-9.

12. Shirisha S, Joshi G, Sahoo SK, Rao YM. Preparation and evaluation of matrix type transdermal patches of domperidone maleate; in vitro and ex vivo characterization. Int J Pharm Educ Res 2017;51:517-24.

13. Patel HV, Bhatt JD, Patel NK. Design and development of transdermal drug delivery for anti-hypertensive drug using different polymeric system. Int J Pharm Chem Sci 2013;2:942-9.

14. Swati H, Kumar K, Nandy BC, Saxena R. Design, formulation and in vitro drug release from transdermal patches containing imipramine hydrochloride as model drug. Int J Pharm Pharm Sci 2017;9:220-5.

15. Ravichandrian V, Manivannan S. Wound healing potential of transdermal patches containing bioactive fraction from the bark of Ficus Racemosa. Int J Pharm Pharm Sci 2015;7:326-32.

16. Ramesh G, Vishnu YV, Kishan V, Rao YM. Development of carvedilol transdermal patches: Physicochemical, Ex vivo and mechanical properties. PDA J Pharm Sci Technol 2008;62:391-401

17. Mandal SC. In vitro release and permeation kinetics of pentazocine from matrix-dispersion type transdermal drug delivery systems. Drug Dev Ind Pharm 1994;20:193-4

18. Gupta JR. Formulation and evaluation of matrix type transdermal patches of glibenclamide. Int J Pharm Sci Drug Res 2009;1:46-50

19. Ramesh G, Vishnu YV, Kishan V, Rao YM. Development of nitrendipine transdermal patches: In vitro and ex vivo characterization. Curr Drug Deliv 2007;4:69-76.

20. Sheetal C, Uday BB, Panchaxari MD, Ajith S. Design and evaluation of transdermal patch of felodipine. Indo Am J pharm Res 2015;5:3035-43.

21. Jose J, Narayanacharyulu R, Mathew M. In vitro, ex vivo and in vivo evaluation of transdermal delivery of felodipine. J Pharm Res 2013;12:54-96.

22. Devi VK, Saisivam S, Maria GR, Deepti PU. Design and evaluation of matrix diffusion controlled transdermal patches of verapamil hydrochloride. Drug Dev Ind Pharm 2003;29:495-503. 